\title{
Revista de la
}

\section{CEPAL}

\author{
Secretario Ejecutivo \\ Gert Rosenthal \\ Secretario Ejecutivo Adjunto \\ Carlos Massad
}

\author{
Director de la Revista \\ Anibal Pinto \\ Secretario Técnico \\ Eugenio Lahera
}

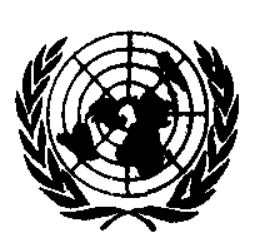

NACIONES UNIDAS

COMISION ECONOMICA PARA AMERICA LATINA Y LL CARIBE

SANTIAGO DE CHILE, AGOSTO DE 1990 


\section{Revista de la}

\section{CEPAL}

Santiago de Chile

Agosto de 1990

Número 41

\section{SUMARIO}

Vigésimo tercer período de sesiones de la CEPAL

Discursos

Secretario Ejecutivo de la CEPAL, Gert Rosenthal.

Presidente de Venezuela, Carlos Andrés Pérez.

Ministro de Economía de Chile, Carlos Ominami.

Secretario de Programación y Presupuesto de México, Emesto Zedillo Ponce de León.

Director para las relaciones con América Latina de la Comisión Europea, Angel Viñas.

La política de estabilización en México, Jorge Eduardo Navarrete.

La intervención del Estado en Brasil. Un enfoque pragmático. Luis Carlos Bresser.

Desarrollo sostenido para el Caribe. Trevor Harker.

La inserción comercial de América Latina. Mattia Barbera.

Elementos para una política ambiental eficaz. Maria Inés Bustamante, Santiago Torres.

Las cuentas del patrimonio natural y el desarrollo sustentable. Nicolo Gligo.

Magnitud de la situación de la pobreza. Juan Carlos Feres, Arturo León.

Areas duras y áreas blandas en el desarrollo social. Rubén Kaztman, Pascual Gerstenfeld.

Naturaleza y selectividad de la política social. Ana Sojo.

Modelos econométricos para la planificación. Eduardo García D'Acuña.

Selección de ventajas comparativas dinámicas. Eduardo García D’Acuña.

Orientaciones para los colaboradores de la Revista de la CEPAL. 
REVISTA DE LA CEPAL No 41

\section{Magnitud de la situación de la pobreza}

\section{Juan Carlos Feres* Arturo León}

En las últimas dos décadas América Latina atravesó dos fases marcadas por signos opuestos: el decenio de 1970. que para la mayoría de los países fue un periodo de crecimiento económico, y aquellos años del decenio de 1980 en que la crisis deterioró fuertemente los niveles de vida de amplios sectores de la población. La evaluación e interpretación adecuada de esos cambios requiere, sin embargo, indicadores que den cuenta, parcial o agregadamente, de las diversas dimensiones de la situación social y del modo en que éstas han evolucionado.

Como una contribución en tal sentido, en este artículo se entregan cifias relativas a la magnitud alcanzada por la pobreza en América Latina en los años en torno a 1980 y 1986 , estimadas mediante el método de las llamadas líneas de pobreza. El estudio comprende 10 países que representan aproximadamente $85 \%$ de la población y $91 \%$ del producto regional: Argentina, Brasil, Colombia, Costa Rica, Guatemala, México, Panamá, Perú. Uruguay y Venezuela. Las cifras de pobreza fueron, a su vez, extrapoladas a un grupo de 19 países de la región y proyectadas al año 1989.

Los resultados generales del estudio señalan que hacia fines de los años ochenta $37 \%$ de los hogares de América Latina se encontraba en situación de pobreza y $17 \%$ en situación de indigencia. Este último guarismo significa que, incluso destinando la totalidad de los ingresos a la alimentación, uno de cada seis hogares no lograba cubrir las necesidades nutricionales de sus miembros. Los resultados indican, asimismo, que había cerca de 183 millones de personas pobres ( 71 millones más que en 1970), alrededor de 88 millones de las cuales eran indigentes, cifra que representa un aumento de cerca de 28 millones respecto del volumen estimado por la clipal para 1970. Uno de los rasgos más salientes de esta comparación es que, a diferencia de lo que ocurría ese año, la pobreza en América Latina es hoy un fenómeno mayoritariamente urbano, a causa tanto de la fuerte expansión de sus principales ciudades como del hecho de que el incremento de los inclices de pobreza se haya concentrado en esas zonas, particularmente durante el perfodo de crisis.

*Los autores son, respectivamente, funcionario de la División de Estadística y Proyecciones de la c:EPal y Consultor de la C:EPAL.

\section{Introducción}

La crisis económica que afectó a los países de América Latina en los años ochenta no sólo puso de manifiesto las insuficiencias estructurales que han caracterizado el desarrollo de la región, sino que agudizó además muchos de los problemas sociales preexistentes, generando así nuevos obstáculos para la movilidad y la cohesión sociales. Esta situación ha hecho más urgente la tarea de idear estrategias que permitan retomar la senda del crecimiento económico sostenido y orientar, al mismo tiempo, el desarrollo hacia el logro de la equidad social, tareas que demandan a su vez profundizar en el conocimiento de la magnitud y características de la población que vive en condiciones de marginalidad y de privación crítica.

Con este propósito, la División de Estadística y Proyecciones de la CEPAL, en el marco del Proyecto Regional para la Superación de la Pobreza (RLA/86/004) del Programa de las Naciones Unidas para el Desarrollo (PNUD) y con la contribución financiera del Fondo de Población de las Naciones Unidas (FNUAP), llevó a cabo un estudio relativo a la dimensión de la pobreza en los paises latinoamericanos. Dicho estudio (CEPAL, 1990) se inscribe en una línea de investigación iniciada por la cepal. a mediados del decenio de 1970, y que pretende no sólo cuantificar la magnitud del fenómeno sino contribuir también a la elaboración de metodologías que permitan identificar a los hogares en condiciones de pobreza y describir sus características, proveyendo información útil para el diseño de políticas orientadas a superarla. ${ }^{1}$

El presente artículo tiene por objeto dar a conocer algunos resultados de ese estudio, particularmente los referidos a la magnitud de la pobreza en América Latina en los años ochenta, así como reseñar brevemente el método utilizado. ${ }^{2}$ Conviene tener presente que este artículo es un resumen, es decir, está constantemente ha-

\footnotetext{
'Además de los autores de este artículo, en el proyecto participaron principalmente María de la Luz Avendaño, Mabel Bullemore y Carlos Daroch, todos de la División de Estadística y Proyecciones de la (E.PAL, y el consultor Jorge Carvajal.

"En una serie de trabajos de apoyo realizados en el marco del proyecto se describen pormenorizadamente los procedimientos adoptados en cada país y en cada fase de la investigación. Para una lista detallada de esos trabajos véase CEPAL, 1990.
} 
ciendo referencia, explicita o no, al estudio original. Así, reduce u omite muchos de los desarrollos del citado estudio, particularmente de aquellos que se ocupan del método empleado para las distintas estimaciones.

Los países incluidos en el estudio son Argentina, Brasil, Colombia, Costa Rica, Guatemala, México, Panamá, Perú, Uruguay y Venezuela. En la mayoría de los casos la medición de la pobreza se refiere a los años 1980 y 1986 , y se ciñe, en lo fundamental, a un procedimiento ya ampliamente difundido en la región, basado en la comparación del ingreso de los hogares con el costo de satisfacción de sus necesidades básicas. ${ }^{3}$ Este método consiste en el cálculo de las denominadas líneas de pobreza, que representan el monto mínimo de ingreso que permite a un hogar -en un momento y lugar determinadosdisponer de recursos suficientes para satisfacer las necesidades básicas de sus miembros, tanto alimentarias como no alimentarias.

Los múltiples aspectos teóricos comprendidos en una investigación de este tipo, que se inscribe en el marco conceptual de las mediciones de la pobreza absoluta, como asimismo las consecuencias de la metodología adoptada para analizar las condiciones de vida de los hogares y delimitar las situaciones de pobreza, ya han sido abordados in extenso en diversos trabajos, entre los que destaca especialmente el estudio de la crist. (Altimir, 1979), referido a la situación de 1970 (en adelante estudio CEPAI-70).

A fin de interpretar adecuadamente los resultados relativos a la magnitud de la pobreza que aquí se presentan, y especialmente el significado de su evolución entre 1980 y 1986, conviene

\footnotetext{
${ }^{3}$ Aun cuando no se recogen en el presente artículo, la investigación avanzó en el examen de ciertos aspectos metodológicos que permiten perfeccionar estas mediciones de la pobreza y otorgarles asimismo un carácter más periódico.
}

tener presente los criterios que guiaron la selección de los años de estimación. En general, se trató de contar con mediciones lo más actualizadas posible, atendiendo a las restricciones de la información existente, la que permitió en la mayoría de los casos efectuar estimaciones para 1986 y para un año posterior en el caso específico de dos países. Además, se seleccionó un año alrededor de 1980 para apreciar el efecto de la crisis sobre los niveles de pobreza y evaluar, asimismo, la magnitud de los cambios ocurridos en la década de 1970; en este sentido el criterio fue seleccionar el año anterior a la crisis y cercano a 1980 en que cada uno de los países exhibió mejores resultados. Ahora bien, el hecho de que el último año para el que se dispuso de información dentro de la década de 1980 haya encontrado a los diferentes países en distintos momentos de la evolución seguida por cada uno de ellos dentro del período de crisis, incide claramente en la magnitud de la pobreza que detectan nuestras mediciones. En efecto, el método de cuantificación que utilizamos descansa fundamentalmente en la magnitud del ingreso corriente de los hogares, que experimentó cambios importantes en el curso de los años ochenta.

En el primer capítulo se describen sumariamente el modo en que se definieron las canastas básicas de alimentos y el método con que se estableció el valor de las líneas de pobreza. Se indican, asimismo, los criterios utilizados para corregir y ajustar los datos de ingreso de los hogares. En el segundo capítulo se presentan las cifras relativas a la magnitud de la pobreza e indigencia en 1980 y 1986 en los 10 países seleccionados y se hacen algunas consideraciones sobre su alcance. El capítulo comprende también una extrapolación de esas cifras de pobreza a 19 países de la región y una proyección de las mismas al año 1989, para terminar comparando estos resultados con estimaciones similares efectuadas en la (XPAl para 1970. 


\section{Las líneas de pobreza y el ingreso de los hogares}

La determinación del valor de una línea de pobreza (que debe compararse con el ingreso corriente de los hogares para estimar la magnitud de la pobreza), se basa, en el cálculo del costo de una canasta básica de alimentos cuya composición cubre las necesidades nutricionales de la población, tomando en cuenta los hábitos de consumo predominantes, la disponibilidad efectiva de alimentos en cada país, y los precios relativos de los mismos. Ese costo es lo que se entiende como línea de indigencia. La línea de pobreza se obtiene, a su vez, sumando al valor de esa canasta los recursos que requieren los hogares para satisfacer el conjunto de las necesidades básicas no alimentarias. En lo que sigue nos referiremos, de manera general, a los procedimientos adoptados para la elaboración de las canastas básicas de alimento, la determinación de las líneas de pobreza, y la estimación de los niveles de ingreso.

\section{Las canastas básicas de alimentos}

El punto de partida para la elaboración de las canastas básicas de alimentos utilizadas en este estudio fue la selección, en cada país y área geográfica, de un estrato poblacional cuya pauta de consumo quedó definida como pauta de referencia. La información correspondiente se obtuvo de las encuestas de ingresos y gastos de los hogares realizadas en los distintos países en los últimos años. ${ }^{4}$ El procedimiento mediante el cual se escogió al grupo de referencia es, a grandes rasgos, el siguiente: primeramente se clasificó al conjunto de las familias encuestadas según el monto de su ingreso per cápita, para luego determinar la ubicación del estrato de referencia en esa escala de ingreso y el tamaño del estrato de acuerdo con dos criterios generales: en primer lugar, el que los hábitos de consumo del grupo en cuestión no

\footnotetext{
${ }^{4} \mathrm{En}$ cl caso de Brasil, no se dispuso de los datos de la encuesta de 1987-1988, por lo que las canastas se elaboraron a partir del Estudo Nacional da Despesa Familiar (ENDFF) de 1974-1975. En Costa Rica tampoco se tuvo acceso a los datos de la encuesta de 1988, de modo que la canasta se basó en los antecedentes del estudio c.:PAI.-70.
}

fuesen expresión de decisiones adoptadas por los hogares en un marco de extrema escasez de recursos; y, en segundo lugar, que dicho grupo fuese de un tamaño tal que su pauta de gasto pudiese considerarse suficientemente representativa. Con estos propósitos se especificaron las ingestas calóricas y proteicas efectivas de distintos estratos de hogares, seleccionándose como grupo de referencia a aquel estrato que - además de cumplir el requisito de la representatividad-sobrepasara levemente, en promedio, el nivel de los requerimientos nutricionales mínimos recomendados. Así, nunca se escogió como estrato de referencia a los hogares de más bajos ingresos; por el contrario, los estratos elegidos quedaron en general ubicados entre los percentiles 20 y 50 de la distribución del ingreso, con las excepciones de Argentina (Gran Buenos Aires) y Uruguay (Montevideo), donde dicho estrato se ubicó entre los percentiles 11 y 35 , y del área urbana no metropolitana de Guatemala (percentiles 50 y 83 ).

La selección de los alimentos se hizo, por su lado, considerando aquellos que representaban una parte significativa del gasto alimentario o que eran consumidos por una proporción importante de los hogares. En esta selección se incluyó también el gasto en bebidas y comidas fuera del hogar.

Las cantidades físicas asociadas a los gastos declarados por los hogares se estimaron mediante los precios registrados por las oficinas nacionales de estadística para el cálculo de los respectivos índices de precios al consumidor (IPC) , y se expresaron en su equivalencia de gramos/día por persona. Las cantidades de calorías y nutrientes correspondientes a esas cantidades físicas se determinaron, a su vez, utilizando los coeficientes de composición nutricional de los alimentos, para lo cual se emplearon las tablas que mejor se adecuaban a la variedad de productos consumidos en cada país.

Ahora bien, de la pauta de consumo del estrato de referencia se excluyeron algunos artículos en razón de su alto precio por caloría, su baja incidencia en el gasto alimentario y su carácter 
relativamente prescindible desde un punto de vista estrictamente nutricional y de complementariedad culinaria. Esta exclusión respondió principalmente al propósito de definir una canasta básica cuya composición, junto con reflejar los hábitos de consumo de la población, redujera al mínimo el efecto encarecedor de la dieta que resulta de promediar la multiplicidad de pautas de consumo que existen en los distintos hogares que conforman un determinado grupo de referencia.

La estructura y composición de la canasta resultante se evaluó a la luz del perfil global de la oferta y la demanda de alimentos del respectivo país, comparándola para tal efecto tanto con la pauta de consumo promedio del conjunto de los hogares, obtenida de la misma encuesta de presupuestos familiares, como con la información relativa a la oferta agregada de alimentos que se extrajo de las hojas de balance correspondientes al trienio 1981-1983 de la Organización de las Naciones Unidas para la Agricultura y la Alimentación (FAO).

Finalmente, las cantidades físicas de todos los artículos de la canasta se ajustaron proporcionalmente de modo que su contenido calórico global coincidiera exactamente con las necesidades promedio de energía de la población del respectivo país y área geográfica. Para este propósito se estimaron los requerimientos nutricionales de la población de esos países basándose en las recomendaciones internacionales vigentes a partir de la Reunión Consultiva Conjunta FAo/oms/end de Expertos de 1981 (Fo/OMS/Lne, 1985). En particular, el cálculo de las necesidades medias de energía y proteínas tomó en consideración tanto la estructura sociodemográfica de las áreas urbanas y rurales de cada país, como la multiplicidad de requerimientos nutricionales que derivan de la amplia variedad de tamaños corporales y tipos de actividad física de las personas. En este sentido, se modificó la perspectiva referida a un adulto tipo que prevalece en las recomendaciones previas (FAo/oms, 1973). ${ }^{5}$

En el cuadro 1 se presentan las canastas bási-

\footnotetext{
${ }^{5}$ Respecto de las necesidades de energía, las estimaciones relativas a los años en torno a 1980 fueron entre 5 y $7 \%$ inferiores a aquellas utilizadas en el estudio CEPAL-70. Una descripción detallada de estos cálculos se encuentra en ci:PAI., 1988.
}

cas según los grupos de alimentos que las componen; en el cuadro 2, en tanto, se muestran algunos indicadores de la calidad nutricional de las mismas. Estos últimos se calcularon en virtud de que las canastas no sólo deben satisfacer requerimientos totales de calorías y proteínas sino que es necesario también que su composición satisfaga determinados estándares dietéticos. Así pues, para la confección de las canastas se tomaron especialmente en consideración, entre otros, aquéllos relacionados con el origen de las calorías según tipos de nutrientes y los relacionados con la calidad de las proteínas. De este modo, se consideró aceptable una dieta que tuviese, en promedio, al menos $10 \%$ de calorías proteicas y entre 15 y $25 \%$ de calorías grasas. Asimismo, se procuró que los cereales y legumbres no aportaran más de $60 \%$ del total de las calorías de la dieta. En cuanto a la calidad de las proteínas, se estimó adecuado que a lo menos $35 \%$ de las mismas fuera de origen animal. Sin perjuicio de reconocer que los parámetros referidos al equilibrio de energía y proteínas constituyen los principales índices de calidad dietética, la aplicación preferente de estos parámetros no implica desconocer, como es evidente, el valor que tienen todos los demás nutrientes en una dieta adecuada. Es por eso que las canastas básicas fuéron adicionalmente evaluadas según su contenido en calcio, hierro, vitamina $A$, tiamina, riboflavina, niacina y vitamina $\mathrm{C}$, encontrándose que, en general, cumplían con los niveles mínimos establecidos para cada uno de estos nutrientes.

Finalmente, para establecer el costo monetario de las canastas de alimentos se utilizaron nuevamente los precios al consumidor de cada artículo recolectados para el cálculo del IPC: excluyéndose el consumo alimentario fuera del hogar o, más precisamente, asimilándolo a la estructura y precios por caloria observados en el consumo dentro del hogar. ${ }^{6}$

\footnotetext{
${ }^{6} \mathrm{El}$ valor de las dietas se expresó también en términos del costo de $1000 \mathrm{kcal}$, como una unidad apropiada para determinar el costo de la alimentación por persona o por hogar, tomando en cuenta en este último caso el requerimiento calórico específico de cada uno de sus miembros. Esto, que representa una medición del costo de la satisfacción de las necesidades alimentarias, según un concepto de adultoequivalente, permitió realizar otros cálculos de la magnitud de la pobreza basados en los requerimientos calóricos de cada hogar (c.PAI., 1990).
} 
Cuadro 1

AMERICA LATINA (DIEZ PAISES): CANASTAS BASICAS DE ALIMENTOS (Gramos diarios por persona)

\begin{tabular}{|c|c|c|c|c|c|c|c|c|c|c|c|c|c|c|c|}
\hline \multirow{2}{*}{ Rubro alimenticio } & \multirow{2}{*}{$\begin{array}{c}\text { Argentina } \\
\begin{array}{c}\text { Gran Buenos } \\
\text { Aires }\end{array}\end{array}$} & \multicolumn{2}{|c|}{ Brasil $^{*}$} & \multicolumn{2}{|c|}{ Colombia } & \multirow{2}{*}{$-\frac{\begin{array}{c}\text { Costa } \\
\text { Rica }\end{array}}{\text { San José }}$} & \multicolumn{3}{|c|}{ Guatemala } & \multicolumn{2}{|c|}{ México } & \multirow{2}{*}{$\frac{\text { Panamá }}{\begin{array}{c}\text { Ciudad de } \\
\text { Panamá }\end{array}}$} & \multirow{2}{*}{$\frac{\text { Perú }}{\text { Lima }}$} & \multirow{2}{*}{$\frac{\text { Lruguay }}{\text { Montevideo }}$} & \multirow{2}{*}{$\begin{array}{c}\text { Venezuel } \\
\text { Caracas. } \\
\text { A.M }^{\mathrm{b}} \text {. }\end{array}$} \\
\hline & & $\begin{array}{l}\text { A.M. } M^{b} \text { de } \\
\text { Rio de } \\
\text { Janeiro }\end{array}$ & 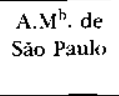 & $\begin{array}{l}\text { Bogotá. } \\
\text { D.E. }\end{array}$ & $\begin{array}{l}\text { Resto } \\
\text { area } \\
\text { urbana }\end{array}$ & & $\begin{array}{c}\text { Area } \\
\text { urbana } \\
\text { central }\end{array}$ & $\begin{array}{c}\text { Resto } \\
\text { área } \\
\text { urbana }\end{array}$ & $\begin{array}{l}\text { Area } \\
\text { rural }\end{array}$ & $\begin{array}{c}\text { Area } \\
\text { urbana }\end{array}$ & $\begin{array}{l}\text { Area } \\
\text { rural }\end{array}$ & & & & \\
\hline Cereales y derivados & 279.7 & 278.0 & 276.7 & 244.6 & 249.0 & 305.2 & 331.2 & 331.1 & 341.5 & 345.2 & 349.4 & 305.0 & 283.7 & 309.7 & 276.7 \\
\hline Tubérculos y raíces & 176.1 & 75.4 & 81.8 & 185.4 & 169.6 & 64.5 & 63.9 & 52.8 & 41.1 & 47.3 & 26.3 & 62.8 & 184.2 & 143.7 & 90.5 \\
\hline Azúcar & 44.2 & 82.4 & 106.1 & 76.4 & 80.5 & 39.7 & 72.5 & 66.3 & 68.4 & 55.5 & 68.7 & 43.0 & 70.4 & 50.7 & 46.1 \\
\hline Legumbres & 6.6 & 65.1 & 62.4 & 28.7 & 24.8 & 25.7 & 39.1 & 50.7 & 55.4 & 45.4 & 44.5 & 23.1 & 11.6 & 4.3 & 16.7 \\
\hline Yerduras & 81.4 & 107.3 & 96.9 & 73.8 & 64.0 & 60.5 & 88.5 & 57.6 & 49.2 & 89.1 & 62.4 & 30.7 & 62.1 & 43.1 & 81.7 \\
\hline Frutas & 107.1 & 92.4 & 68.0 & 165.8 & 165.6 & 113.8 & I 39.3 & 93.9 & 72.6 & 109.7 & 91.3 & 98.5 & 116.6 & $9 \overline{5} .1$ & 159.9 \\
\hline Pescados y mariscos & 6.7 & 20.7 & 18.2 & 8.3 & 5.5 & 5.2 & 8.2 & 10.3 & 10.7 & 7.0 & 7.5 & 20.5 & 19.1 & 5.1 & 14.4 \\
\hline Lechey derivados & 226.5 & 140.7 & 106.0 & 185.3 & 178.5 & 142.8 & 144.0 & 123.7 & 105.9 & 185.6 & 133.3 & 151.2 & 137.8 & 294.9 & 193.1 \\
\hline Huevos & 23.3 & 22.2 & 14.0 & 30.1 & 20.0 & 19.2 & 35.3 & 29.7 & 21.0 & 46.0 & 35.5 & 16.2 & 18.2 & 10.9 & 17.2 \\
\hline Bebidas & 113.3 & 34.8 & 25.1 & 113.6 & 77.9 & 86.3 & 78.2 & 62.9 & 54.7 & 95.2 & 74.3 & 104.1 & 77.0 & 89.0 & 116.7 \\
\hline Aceites $y$ grasas & 30.7 & 35.3 & 31.6 & 23.8 & 25.2 & 20.5 & 19.0 & 14.2 & 11.2 & 27.5 & 25.1 & 27.9 & 20.1 & 23.6 & 19.4 \\
\hline Total & 1277.3 & 1055.1 & 963.0 & l 248.4 & 1174.6 & 1014.1 & 1126.6 & $981 . \overline{5}$ & 910.8 & 1170.3 & 1018.2 & 1024.5 & 1108.8 & I 213.5 & 1168.1 \\
\hline
\end{tabular}

Fuente: Estimaciones de la cePAL, basadas en tabulaciones especiales de encuestas de ingresos y gastos de los hogares.

- Las canastas básicas de alimentos correspondientes a las distintas regiones de Brasil se incluyen en el Anexo B. 1 del documento "Magnitud de la pobreza

en América Latina en los años ochenta", CEPAL, LC/L. 533, Santiago de Chile, junio de 1990

b A.M. = Area Metropolitana. 
Cuadro 2

AMERICA LATINA (DIEZ PAISES): SINTESIS DE LA COMPOSICION NUTRICIONAL DE LAS CANASTAS BASICAS DE ALIMENTOS

\begin{tabular}{|c|c|c|c|c|c|c|}
\hline \multirow[b]{2}{*}{ P’aís } & \multicolumn{2}{|c|}{ Cantidad de: } & \multicolumn{3}{|c|}{ Calorías provenientes de: } & \multirow{2}{*}{$\begin{array}{c}\text { Proteínas } \\
\text { de origen } \\
\text { animal }\end{array}$} \\
\hline & $\begin{array}{c}\text { Calorías } \\
\text { (kcal/día } \\
\text { por persona) }\end{array}$ & $\begin{array}{c}\text { Proteínas } \\
\text { (grs/día } \\
\text { por persona) }\end{array}$ & Proteínas & $\begin{array}{c}\text { Grasas } \\
\text { (porcentajes) }\end{array}$ & $\begin{array}{c}\text { Cereales } \\
\text { y legumbres } \\
\text { (porcentajes) }\end{array}$ & \\
\hline \multicolumn{7}{|l|}{ Argentina } \\
\hline (;ran Buenos Aires & 2211 & 79.0 & 14.3 & - & 42.2 & 55.5 \\
\hline \multicolumn{7}{|l|}{ Brasili" } \\
\hline Rio de Janeiro A.M'. & 2214 & 71.0 & 12.8 & 23.6 & 49.8 & 43.9 \\
\hline São Paulo, A.M. & 2152 & 66.2 & 12.3 & 25.7 & 50.3 & 42.0 \\
\hline \multicolumn{7}{|l|}{ Colombia } \\
\hline Bogotá, D.E. & 2151 & 65.7 & 12.2 & 23.1 & 41.0 & 48.4 \\
\hline Resto área undana & 2151 & 63.2 & 11.7 & 22.5 & 42.6 & 49.9 \\
\hline \multicolumn{7}{|l|}{ Costa Rica } \\
\hline San José & 2167 & 69.9 & 12.9 & 24.5 & 51.2 & 40.7 \\
\hline \multicolumn{7}{|l|}{ (;uatemala } \\
\hline Area curbana central & 2135 & 64.4 & 12.1 & 24.6 & 53.8 & 45.3 \\
\hline Resto área urbana & 2135 & 63.6 & 11.9 & 22.0 & 61.5 & 40.2 \\
\hline Area rura! & 2150 & 62.6 & 11.7 & 19.7 & 66.3 & 36.0 \\
\hline \multicolumn{7}{|l|}{ México } \\
\hline Area urbana & 2125 & 65.3 & 12.3 & 28.7 & 51.1 & 46.9 \\
\hline Area rural & 2165 & 60.8 & 11.2 & 25.9 & 56.6 & 40.1 \\
\hline \multicolumn{7}{|l|}{ Pancmá } \\
\hline Ciudad de Panamá & 2138 & 69.3 & 13.0 & 23.2 & 53.2 & 51.2 \\
\hline \multicolumn{7}{|l|}{ Perú } \\
\hline Lima metropolitana & 2154 & 70.1 & 13.0 & 19.8 & 47.2 & 50.0 \\
\hline \multicolumn{7}{|l|}{ Uruguay } \\
\hline Montevideo & 2152 & 73.5 & 13.7 & - & 47.0 & 51.8 \\
\hline \multicolumn{7}{|l|}{ Venezuela } \\
\hline (aracas, A.M." & 2140 & 70.2 & 13.1 & 19.2 & 48.0 & 54.2 \\
\hline
\end{tabular}

Fuente: Estimaciones de la cEPAl, basadas en tabulaciones especiales de encuestas de ingresos y gastos de los hogares.

"Una síntesis de la composición nutricional de las canastas básicas de alimentos de las distintas regiones de Brasil se encuentra en el anexo B.4 del documento Magnitud de la pobreza en América Latina en los años ochenta, (E.PAL, Lc:/..533, Santiago de Chile, junio de 1990.

ts A.M. = Area Metropolitana.

En síntesis, puede considerarse que las canastas propuestas, pese a estar basadas en la observación del consumo efectivo de alimentos de estratos representativos de la población de cada país, son normativas, toda vez que no reproducen exactamente el nivel y estructura de las ingestas alimentarias de dichos estratos. En efecto, tal como se ha señalado, las dietas se ajustaron a ciertos requerimientos mínimos en materia de energía y proteínas, se adecuaron a la disponibilidad interna de alimentos y fueron, además, modificadas, sustituyendo o eliminando algunos bienes en atención a su costo o al carácter pres- cindible de los mismos, sin implicar por ello canastas de costo mínimo.

\section{Las líneas de pobreza}

El procedimiento seguido para determinar las líneas de pobreza consistió en establecer, en términos normativos, a partir de los presupuestos básicos de alimentación (o líneas de indigencia), relaciones entre los gastos en alimentos y los otros gastos de consumo. ${ }^{7}$ Con ese fin se analiza-

${ }^{7}$ Para un análisis de las implicaciones conceptuales de este procedimiento véase (EPAl., 1990. 
ron en detalle el nivel y estructura del gasto monetario de los hogares de distintos grupos de ingreso, y, en particular, la distribución del gasto entre bienes alimentarios y no alimentarios, especialmente en el estrato poblacional de referencia.

A partir de los valores observados se estimó adecuado adoptar para las áreas urbanas un presupuesto de consumo privado (línea de pobreza) igual al doble del correspondiente presupuesto básico de alimentación. ${ }^{8}$ En el caso de las áreas rurales, en cambio, se supuso que el gasto en alimentos representaba cerca de $57 \%$ del gasto total, de modo que la línea de pobreza rural se obtuvo multiplicando el gasto en alimentos por un coeficiente igual a 1.75 . Ambos criterios coinciden, por lo demás, con aquellos empleados sobre el particular por el estudio cripas-70.

Estos coeficientes se aplicaron de manera uniforme para obtener las líneas de pobreza de las áreas urbanas y rurales. Sin embargo, en los casos en que no se dispuso de información sobre la estructura del consumo de alimentos de los hogares o sobre los precios de los mismos para todas las zonas del país, fue necesario adoptar supuestos relativos a la composición y costo de las canastas alimentarias. Se supuso, en síntesis, que el costo de alimentación en las zonas urbanas no metropolitanas y en las zonas rurales era equivalente a 95 y $75 \%$, respectivamente del costo correspondiente en las áreas metropolitanas o ciudades capitales. En el cuadro 3 pueden apreciarse, expresados en moneda nacional y en dólares estadounidenses, los valores de las líneas de pobreza que resultan de la aplicación de estos criterios.

Conviene señalar que en este marco metodológico para la estimación de los niveles de pobreza, la determinación del costo de satisfacción de las necesidades alimentarias básicas se asienta sobre bases más sólidas que aquellas en las que descansa la estimación relativa a las necesidades no alimentarias. En efecto, mientras las primeras se calculan con arreglo o normas de común acep-

\footnotetext{
${ }^{8} \mathrm{La}$ aplicación uniforme de esta norma puede traer consigo cierto grado de subestimación (o sobreestimación) de la pobreza en los países y áreas de mayor (o menor) desarrollo relativo, donde el coeficiente del gasto en alimentación, para los niveles pertinentes de ingreso, es inferior (o superior) a $50 \%$.
}

tación, que establecen ciertos mínimos o determinados grados de adecuación de las dietas, haciendo explícitos no sólo el costo sino también los bienes que satisfacen dichas necesidades y las características de los mismos, las necesidades no alimentarias - aun cuando en principio podrían también sujetarse a determinadas normas- se valoran por vía indirecta, esto es, a partir de la proporción que representa el gasto en alimentos dentro del gasto total de los hogares. De modo que, si bien se establece indirectamente su costo, no se especifican los bienes que satisfacen esas necesidades. Por otro lado, el hecho de que su satisfacción tenga un costo que varía significativamente a lo largo de las etapas del ciclo de vida familiar -esto es, según el tamaño y composición del hogar-, así como en función de factores tales como el monto del patrimonio acumulado y el grado de acceso a los servicios públicos, hace indispensable un análisis pormenorizado de estos capítulos del gasto que permita en principio definir, tal como en el caso de la alimentación, coeficientes específicos para distintos tipos de hogares."

\section{Los ingresos de los hogares}

Una vez determinados los presupuestos básicos de alimentación y las respectivas líneas de pobreza, se procedió a calcular el monto del ingreso disponible de los hogares, a fin de compararlo con el costo que importa la satisfacción de las necesidades básicas. La principal fuente de información al respecto fueron las encuestas de hogares de propósitos múltiples que efectúan regularmente los países.

Los datos relativos al ingreso que proporcionan estas encuestas suelen estar afectados por

\footnotetext{
${ }^{9} \mathrm{El}$ análisis de la encuesta de ingresos y gastos de Colombia de 1984-1985, por ejemplo, reveló que los hogares con similares niveles de ingreso pero de distinta composición exhiben importantes diferencias en lo que toca a los principales rubros que conforman el gasto no alimentario. Así, el conjunto de los hogares de Bogotá, Cali y Medellín, que conformaban el segundo cuartil de gasto per cápita, mostró diferencias significativas en la proporción del gasto destinado a transporte, educación, salud y vivienda. Cabe señalar, en tal sentido, que los hogares constituidos por parejas jovenes sin hijos destinaban en promedio cerca de $20 \%$ del gasto a vivienda, en tanto que en los hogares de parejas de mayor edad con dos hijos dicho porcentaje era de $15 \%$.
} 
Cuadro 3

AMERICA LATINA (DIEZ PAISES): LINEAS DE POBREZA Y LINEAS DE INDIGENCIA.

PRESUPUESTOS MENSUALES POR PERSONA EN MONEDAS NACIONALES Y DOLARES

(A precios de $1988,2^{\circ}$ semestre)

\begin{tabular}{|c|c|c|c|c|}
\hline \multirow{2}{*}{ Países" } & \multicolumn{2}{|c|}{$\begin{array}{c}\text { Lineas en monedas } \\
\text { nacionales }\end{array}$} & \multicolumn{2}{|c|}{ Líneas en dólares ${ }^{\mathrm{b}}$} \\
\hline & Pobreza & Indigencia & Pobreza & Indigencia \\
\hline \multicolumn{5}{|l|}{ Argentina } \\
\hline Gran Buenos Aires & 761.4 & 380.7 & 63.1 & 31.5 \\
\hline Resto área urbana & 723.3 & 361.7 & 59.9 & 30.0 \\
\hline Area rural & 499.7 & 285.5 & 41.4 & 23.6 \\
\hline \multicolumn{5}{|l|}{ Brasil } \\
\hline Area Metropolitana ${ }^{c}$ & 22958.2 & 11479.1 & 57.0 & 28.5 \\
\hline Resto área urbana & 20181.9 & 10091.0 & 50.1 & 25.0 \\
\hline \multirow{2}{*}{\multicolumn{5}{|c|}{ Colombia }} \\
\hline & & & & \\
\hline Bogotá, I).I.. & 18464.0 & 9232.0 & 58.1 & 29.0 \\
\hline Resto área urbana & 16954.6 & 8477.3 & 53.3 & 26.7 \\
\hline Area rural & 12117.0 & 6924.0 & 38.1 & 21.8 \\
\hline \multicolumn{5}{|l|}{ Costa Rica } \\
\hline San José & 4098.0 & 2049.0 & 52.7 & 26.3 \\
\hline Resto área urbana & 3893.1 & 1946.6 & 50.1 & 25.0 \\
\hline Area rural & 2689.3 & 1536.8 & 34.6 & 19.8 \\
\hline \multicolumn{5}{|l|}{ Guatemala } \\
\hline Area urbana central & 140.3 & 70.2 & 51.9 & 26.0 \\
\hline Resto área urbana & 113.4 & 56.7 & 41.9 & 21.0 \\
\hline Area rural & 84.4 & 48.2 & 31.2 & 17.8 \\
\hline \multicolumn{5}{|l|}{ México } \\
\hline Area urbana & 120827.1 & 60413.5 & 53.0 & 26.5 \\
\hline Area rural & 88135.0 & 50362.9 & 38.6 & 22.1 \\
\hline \multicolumn{5}{|l|}{ P'anamá } \\
\hline Ciudad de Panamá & 67.6 & 33.8 & 67.6 & 33.8 \\
\hline Resto área urbana & 64.2 & 32.1 & 64.2 & 32.1 \\
\hline Area rural & 44.4 & 25.4 & 44.4 & 25.4 \\
\hline \multicolumn{5}{|l|}{ Perú } \\
\hline Lima metropolitana & 12031.0 & 6015.5 & 53.6 & 26.8 \\
\hline Resto área urbana & 11429.4 & 5714.7 & 50.9 & 25.4 \\
\hline Area rural & 7895.3 & 4511.6 & 35.1 & 20.1 \\
\hline \multicolumn{5}{|l|}{ Uruguay } \\
\hline Montevideo & 20674.1 & 10337.0 & 51.5 & 25.8 \\
\hline Resto área urbana & 19640.4 & 9820.2 & 49.0 & 24.5 \\
\hline Area rural & 13567.4 & 7752.8 & 33.8 & 19.3 \\
\hline \multicolumn{5}{|l|}{ Venezuela } \\
\hline Caracas, A.M. & 1906.4 & 953.2 & 70.6 & 35.3 \\
\hline Resto área urbana & 1811.1 & 905.6 & 67.1 & 33.5 \\
\hline Area rural & 1251.1 & 714.9 & 46.3 & 26.5 \\
\hline
\end{tabular}

Fuente: Estimaciones de la CEPAl.

a Sólo se indican en cada país aquellas ciudades o áreas geográficas para las cuales fue posible hacer una estimación detallada de la canasta básica de alimentos y de su costo (línea de indigencia).

b Se utilizó el tipo de cambio serie "rf" (promedio del $2^{\circ}$ semestre de 1988) publicado en Estadísticas financieras internacionales, del Fondo Monetario Internacional. En el caso de Venezuela se utilizo el tipo de cambio vigente en febrero de 1989.

c Promedio ponderado de los presupuestos estimados para Săo Paulo y Río de Janeiro. 
problemas relativos al carácter parcial del concepto de ingreso que se investiga, al hecho de que las personas tienden en general a declarar ingresos inferiores a los que realmente perciben, a una cobertura geográfica restringida, y debido también a factores y contingencias que guardan relación con aspectos teóricos y prácticos del diseño muestral, todo lo cual incide en la calidad y exactitud de las estimaciones. Por tales razones, antes de efectuar las mediciones de pobreza, se procedió a corregir y ajustar el monto de los ingresos captados por las encuestas. Para ello se utilizaron como patrón de referencia cuantitativo las partidas de la cuenta de ingresos y gastos de los hogares del sistema de cuentas nacionales. ${ }^{10}$

En términos generales, el método de ajuste de los ingresos de las encuestas de hogares consistió en imputar a cada tipo o corriente de ingreso investigado las discrepancias observadas entre la declaración y el concepto correspondiente registrado en las cuentas nacionales. Dicha imputación operó sobre la base de los siguientes supuestos: que la subdeclaración de ingresos en las encuestas está asociada más al tipo de ingreso que a la magnitud del mismo; que el monto no declarado de cada tipo de ingreso es igual a la discrepancia entre aquél que consigna la encuesta y la estimación correspondiente que figura en las cuentas nacionales; y que la subdeclaración de cada tipo de ingreso sigue, en general, un patrón de elasticidad unitaria, con excepción de los ingresos de la propiedad en efectivo, ingresos que se supuso concentrados en el quintil de más altos ingresos de la distribución (Altimir, 1987).

Los diferentes tipos de ingreso recogidos por

\footnotetext{
"Véase especialmente, C.F.PAL, 1989 a.
}

la encuesta como los provenientes de las cuentas nacionales, se expresaron en valores per cápita; la comparación entre estos promedios permitió definir coeficientes de ajuste para cada fuente de ingreso. También se calcularon los montos correspondientes a aquellas corrientes no cubiertas por las encuestas.

En las pocas situaciones en que el monto de algún tipo de ingreso estimado por la encuesta fue, en promedio, superior al correspondiente de las cuentas nacionales, no se efectuó ajuste para ese concepto. Por su lado, tanto sueldos y salarios como ganancias empresariales, desglosados todos en agrícolas y no agrícolas, se ajustaron en proporción con los niveles declarados por los receptores de tales ingresos. Igual criterio se aplicó para la súbestimación de las transferencias, con la salvedad de que en aquellos casos en que sólo se captaban ingresos primarios, la imputación recayó sobre las personas inactivas pertenecientes a la categoría de jubilados y pensionados. Del mismo modo, el ajuste por subdeclaración de los ingresos de la propiedad en efectivo se asignó proporcionalmente a los individuos pertenecientes al $20 \%$ de los hogares de más altos ingresos que declararon recibirlos. Por último, el no registro o subestimación del alquiler imputado se distribuyó en proporción al monto del ingreso total - ya ajustado por todos los otros conceptos- de aquellos hogares que declararon habitar en una vivienda propia. ${ }^{11}$

\footnotetext{
"En CEPAl., 1990, Anexo E, pueden encontrarse las estimaciones de la distribución del ingreso por deciles de hogares clasificados según el monto de su ingreso per cápita, correspondientes a los distintos países hacia 1986.
} 


\section{II}

\section{La magnitud y evolución de la pobreza}

Las líneas de pobreza, conjuntamente con las estimaciones del ingreso per cápita de los hogares debidamente corregido, permitieron determinar la magnitud de la pobreza y la indigencia en los años en torno a 1980 y a $1986 .{ }^{12}$ Antes de presentar estos resultados, es necesario, sin embargo, hacer algunas consideraciones generales que precisan el significado y alcance de los mismos.

\section{Consideraciones previas}

En primer lugar, la calidad de las bases de información en las que se sustentan las estimaciones de pobreza que se presentan a continuación no es pareja: difiere de un país a otro $y$, especialmente, en las distintas áreas geográficas de cada país. Puede afirmarse que las mediciones correspondientes a las áreas metropolitanas son en general más precisas que las referidas a las zonas urbanas restantes y a las zonas rurales, en la medida en que las primeras derivan de una información más abundante y confiable. Así, por ejemplo, para elaborar los presupuestos de alimentación se dispuso de más antecedentes sobre las principales ciudades que sobre las demás zonas, en lo relativo tanto a los ingresos y gastos de los hogares como a los precios de los artículos considerados en las canastas básicas de alimentos. Además, como es bien sabido, las encuestas de hogares captan mejor la situación de la población urbana que la de la rural, particularmente en lo que se refiere a la medición de los ingresos. En consecuencia, las cifras de pobreza rural que se proveen en este artículo deben considerarse más

\footnotetext{
${ }^{12}$ Estas mediciones se efectuaron en todos los casos a partir del ingreso per cápita de los hogares y no del gasto. Esta decisión respondió al hecho de que los antecedentes relativos a los gastos se limitan en la maroría de los paises de bat región a las áreas metropolitanas o a las ciudades capitales. Asimismo. el hecho de que estat información se recoja normalmente cada I0 anos. impide medir de manema más frecuente la pobreza basándose en el nivel de gasto de los hogares. lo que sí se logra a partir de los datos de ingreso que proveen las encuestas de propósitos multiples que la mavoría de los países lleva a cabo regularmente.
}

bien como indicativas de órdenes de magnitud. Más aún, tanto en el caso del resto urbano y del área rural de Argentina como en el del área rural de Uruguay, las estimaciones tienen un carácter meramente conjetural. Igual cosa ocurre con el área rural de Colombia y el resto urbano y el área rural de Perú en los años cercanos a 1980. Estas estimaciones se presentan, pues, con el solo propósito de ofrecer una visión a nivel nacional de los distintos países que permita incluirlos en las comparaciones internacionales.

En segundo lugar, el mayor sustento normativo y empírico en que descansa el cálculo del costo de la satisfacción de las necesidades alimentarias en comparación con el de las otras necesidades básicas, hace que las estimaciones de pobreza, a diferencia de las de indigencia, dependan de cuán adecuados sean en cada caso particular, los coeficientes utilizados para determinar las líneas de pobreza, esto es, el valor 2 para las áreas urbanas y 1.75 para las rurales.

En tercer lugar, si bien es cierto que el fenómeno de la pobreza responde esencialmente a características estructurales de los países -lo que hace suponer que su magnitud cambia con relativa lentitud en el tiempo-- el método utilizado para estimarla es, por su misma naturaleza, bastante sensible a aquellas circunstancias coyunturales que implican cambios significativos en el nivel de ingreso de los hogares. En tal sentido, los resultados deben examinarse prestando atención tanto a los años a los cuales se refieren las cifras en cada país como, muy especialmente, a la fase por la que atravesaban estos países dentro del ciclo recesivo que afectó a América Latina desde comienzos de la década de 1980. La advertencia anterior exige, pues, especial cautela al momento de extraer conclusiones sobre la evolución de la magnitud de la pobreza y el desempeno comparativo de los distintos países a ese respecto.

En este orden de ideas, cabe mencionar que la sensibilidad de estas medidas de pobreza ante las variaciones en el nivel del ingreso depende también del perfil de la distribución de éste, así como de la distancia a que se encuentren las 
líneas de indigencia y de pobreza respecto de los valores modales de esa distribución. En efecto, un país en el cual una alta proporción de los hogares perciba ingresos que se encuentren en torno al valor de esas líneas, presentará oscilaciones importantes en la magnitud de la indigencia y la pobreza ante cambios relativamente pequeños en el monto de los ingresos. ${ }^{13}$

Por último, es pertinente hacer notar que las líneas de pobreza e indigencia permiten clasificar el conjunto de los hogares pobres en dos subgrupos: el de los indigentes y el de los pobres no indigentes. De los primeros puede afirmarse que son hogares cuyos miembros muy probablemente no satisfacen ninguna de sus necesidades básicas. Por otro lado, no necesariamente todos los hogares del subgrupo de los pobres no indigentes satisfacen en forma adecuada sus requerimientos alimentarios, porque, aunque su ingreso es superior al presupuesto básico de alimentación, deben asignar una fracción del mismo a atender las necesidades restantes.

\section{Resultados para 1980 y 1986}

La simple observación de las incidencias porcentuales de pobreza e indigencia que presenta el cuadro 4 para los años cercanos a 1980 y 1986 , permite advertir una gran diversidad de situaciones. Por un lado, Argentina y Uruguay son los países que exhibieron los más bajos porcentajes de pobreza de la región: en efecto, en ambas fechas ésta tocaba a menos de uno de cada seis hogares. Guatemala y Perú se sitúan en el otro extremo: en el primer caso la pobreza alcanzaba a cerca de las dos terceras partes de los hogares; en el segundo, a cerca de la mitad. Entre estos polos se ubican dos grupos de países en los que la pobreza afectaba a entre 20 y $40 \%$ de los hogares. Al primer grupo - más próximo al $20 \%$ - pertenecen Costa Rica, Venezuela y México, en tanto que en el segundo -más cerca del $40 \%$ - se inscriben Panamá, Colombia y Brasil.

Asimismo, la proporción de hogares indi-

\footnotetext{
${ }^{13}$ De esta característica, propia del método aquí adoptado, deriva también la comveniencia de medir la polbreza on forma periódica (anual o bianual), medición que permitiría utilizar este indice sintétios para esaluar regularmente los cambios en las condiciones de vida de la población.
}

gentes varía también ampliamente de un país a otro, desde niveles cercanos a $5 \%$, en Argentina y Uruguay, hasta porcentajes superiores al $20 \%$ e incluso al $30 \%$ en Perú y Guatemala, respectivamente. Los países restantes se ordenan entre esos valores extremos, en forma similar a lo observado respecto de los índices de pobreza. Cabe destacar que los cambios ocurridos entre 1980 y 1986 no llegaron a alterar la posición que ocupaban inicialmente los países en la escala de pobreza.

La comparación entre las áreas geográficas subnacionales pone igualmente en evidencia las pronunciadas disparidades en los niveles de bienestar de la población dentro de cada país: los porcentajes más bajos de pobreza corresponden a las zonas urbanas y, dentro de éstas, a las principales ciudades $o$ áreas metropolitanas, en tanto que los más altos se observan en las áreas rurales. No obstante, estas diferencias varían considerablemente de un país a otro, lo que refleja distintos grados de heterogeneidad interna en los niveles de ingreso de la población. Así, por ejemplo, si se comparan las situaciones de Brasil y Colombia, al respecto, podrá apreciarse que, aunque ambos exhiben un nivel similar de pobreza urbana, cercano en cada caso a la tercera parte de los hogares, la pobreza rural en Brasil es superior en casi 30 puntos porcentuales a la pobreza urbana, en tanto que en Colombia esta diferencia es inferior a 10 puntos porcentuales. Guatemala y Perú están en una relación semejante, pero con niveles de pobreza más altos. Debe tenerse presente, por otro lado, que los dos son, junto con Costa Rica, los países que tienen mayor proporción de población rural.

Las consideraciones que acabamos de hacer no dejan de ser importantes desde un punto de vista cuantitativo, dado que los índices nacionales de pobreza se calcularon precisamente como un promedio ponderado de los índices de las distintas áreas geográficas, y están, por eso mismo, influidos no sólo por la incidencia de la pobreza en cada una de ellas sino también por la importancia relativa de esas áreas dentro de la población total del país. La comparación de las cifras correspondientes a Costa Rica y Venezuela ilustra el efecto que ejercen las aludidas diferencias urbano-rurales (cuadro 4). En 1988 Costa Rica tenía $21 \%$ de los hogares urbanos y $28 \%$ de los rurales bajo la línea de pobreza; en Venezuela, 
Cuadro 4

AMERICA LATINA (DIEZ PAISES): HOGARES EN SITLACION DE POBREZA E INDIGENCIA

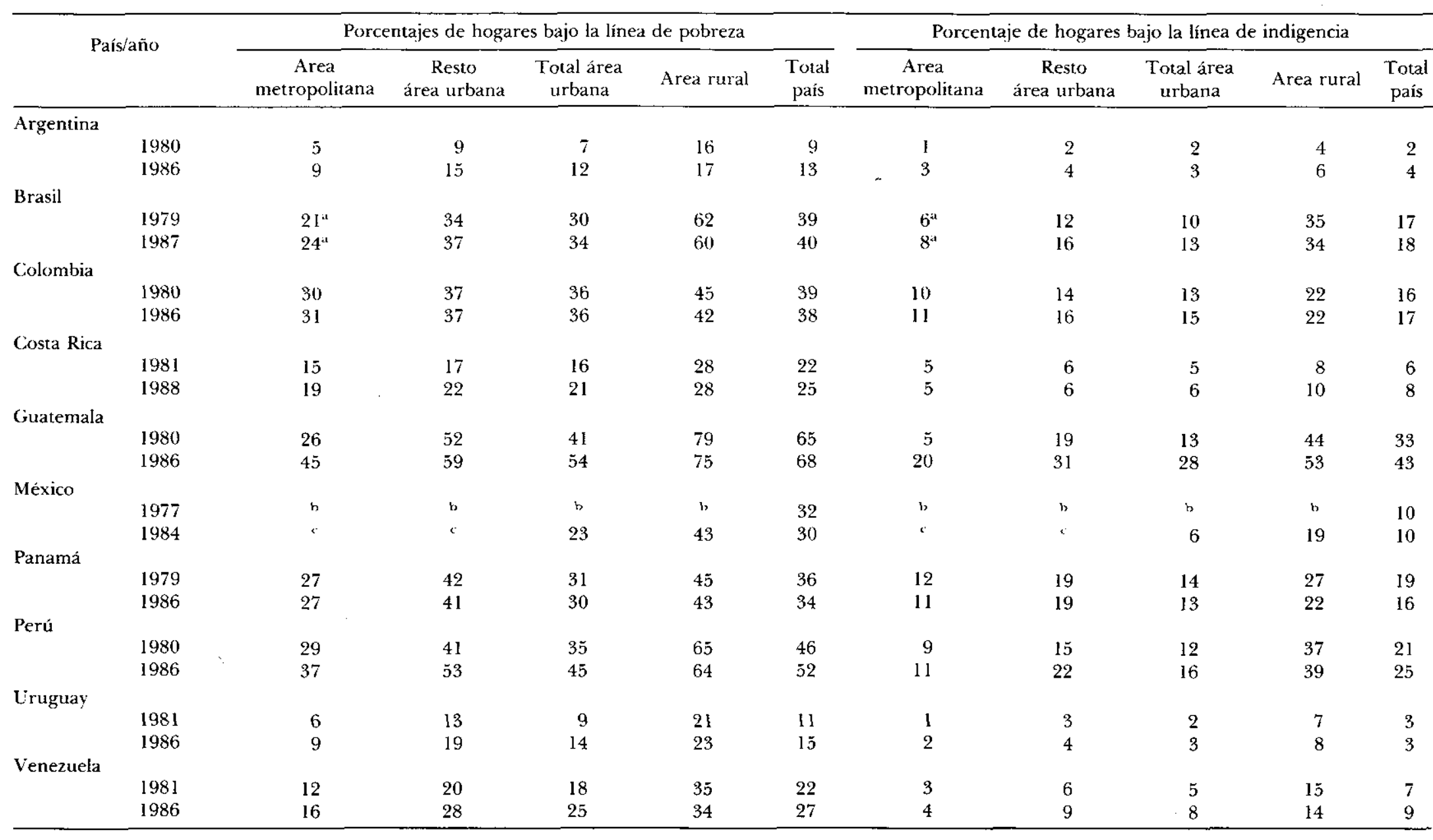

Fuente: Estimaciones de la CEPAL, basadas en tabulaciones especiales de las encuestas de hogares.

a Promedio ponderado de las estimaciones correspondientes a las áreas metropolitanas de Río de Janeiro y São Paulo.

b Sólo se dispuso de antecedentes a nivel nacional.

La encuesta de hogares utilizada para la estimación no es representativa a nivel del Distrito Federal. 
entretanto, las cifras eran, en 1986, de 25 y $34 \%$, respectivamente. Esta diferencia favorable a Costa Rica se atenúa sin embargo a nivel nacional - Costa Rica presentaba una pobreza global equivalente a $25 \%$ y Venezuela a $27 \%$ - debido precisamente al hecho de que en el primero la población rural constituía ese año $54 \%$ de la población total, contra apenas $20 \%$ en el caso de Venezuela.

Aunque en este artículo no se exponen detalladamente las incidencias de pobreza en términos individuales, el hecho de que los hogares pobres estén compuestos en general por mayor número de personas que los no pobres hace que el porcentaje de personas afectadas por la pobreza sea mayor que el de hogares en esa situación. De ese modo, en los años cercanos a 1980 y 1986 , los índices de pobreza expresados en términos de personas fueron, en las zonas urbanas, entre 3 y $7 \%$ superiores a los índices de pobreza de los hogares, y entre 3 y $9 \%$ en las zonas rurales.

Debe tenerse presente en lo que toca a la evolución de la pobreza en los años ochenta, que no puede considerarse que el período cubierto por nuestro análisis en cada país, por más que comprenda algunos años de fuerte caída del ingreso, refleje siempre en toda su intensidad la profundidad de la crisis. En efecto, sólo en cinco de los 10 países el último año de estimación coincide con el año en que el producto llegó a su punto más bajo: así ocurrió con Venezuela y Guatemala en 1986, y, parcialmente, con Argentina (1986), Perú (1985) y Uruguay (1986). No debe extrañar entonces que sea precisamente en estos países donde se constatan los aumentos más fuertes de las incidencias de pobreza, tanto a nivel nacional (entre cuatro y seis puntos porcentuales) como, particularmente, en las áreas urbanas (entre cinco y 13 puntos). Estas cifras, junto con los aumentos relativamente menores - $\mathrm{e}$ incluso las leves disminuciones- de la pobreza rural en este período (de uno a cuatro puntos), muestran que la crisis afectó de modo más agudo a las zonas urbanas. La evolución negativa de los principales indicadores sobre niveles de ingreso y condiciones de bienestar de la población, especialmente los referidos a la población urbana, refuerzan esta apreciación. Así, el ingreso nacional por habitante en Argentina, Guatemala, Uruguay y Venezuela fue en 1986 aproximadamente $20 \%$ más bajo que el que se había alcanza- do hacia 1980. En Perú, por su lado, fue $13 \%$ más bajo en 1985, año en que el ingreso alcanzó su menor nivel dentro del período. Del mismo modo, las tasas de desempleo abierto en las áreas urbanas de los tres primeros países mencionados aumentaron persistentemente durante ese período, hasta casi duplicar en 1986 los niveles que tenían en los años 1980-1981. En Perú, en cambio, aunque no hubo una variación significativa en el desempleo entre los años extremos, las remuneraciones medias cayeron cerca de $23 \%$ entre 1980 y $1985 .^{14}$

Costa Rica también experimentó un incremento (de tres puntos) en el porcentaje de hogares pobres, que se concentró fundamentalmente en las zonas urbanas. Sin embargo, debe tenerse presente que, después de la fuerte caída que sufrió en 1982 respecto de 1981 , el ingreso tendió a crecer sostenidamente hacia 1988 -aunque sin recuperar los niveles que tenía a fines de la década anterior-, de manera que el período dentro del cual se efectuó la medición de pobreza (1981-1988) no da cuenta totalmente del impacto de la crisis. Similar es, en este sentido, la situación de Brasil: la caída del ingreso se dio aquí entre 1980 y 1983 , para alcanzar luego, en 1987 , un nivel levemente superior al de 1979. El aumento en un punto porcentual de la pobreza a nivel nacional (de 39 a $40 \%$ ) también se concentró en las áreas urbanas y metropolitanas, y estuvo acompañado por un leve descenso de la pobreza rural (de 62 a $60 \%$ ). En este caso, pese a la recuperación que pareció insinuar el nivel del empleo, el salario mínimo real seguía siendo hacia 1987 cerca de $25 \%$ más bajo que el del año inicial, 1979.

En Colombia, México y Panamá disminuyó la incidencia de la pobreza, disminución que se explica, en los casos de Colombia y Panamá por la reducción en dos y tres puntos, respectivamente, de la pobreza rural, ya que durante el período considerado prácticamente no hubo cambios en la pobreza urbana en ninguno de los dos países, como tampoco, por otro lado, caídas significativas del producto y del ingreso nacional. En Panamá, el ingreso por habitante en 1986 fue $20 \%$ superior al de 1979, y en Colombia, el mismo año, $5 \%$ superior al de 1980 , aunque el desem-

\footnotetext{
${ }^{1.4}$ Véase CEPAL, $1989 \mathrm{a}$.
} 
Gráfico $1^{\text {:a }}$

AMÉRICA LATINA (DIEZ PAÍSES): RELACIÓN ENTRE LA MAGNITUD

DE LA POBREZA Y EL NIVEL DE INGRESO, 1980

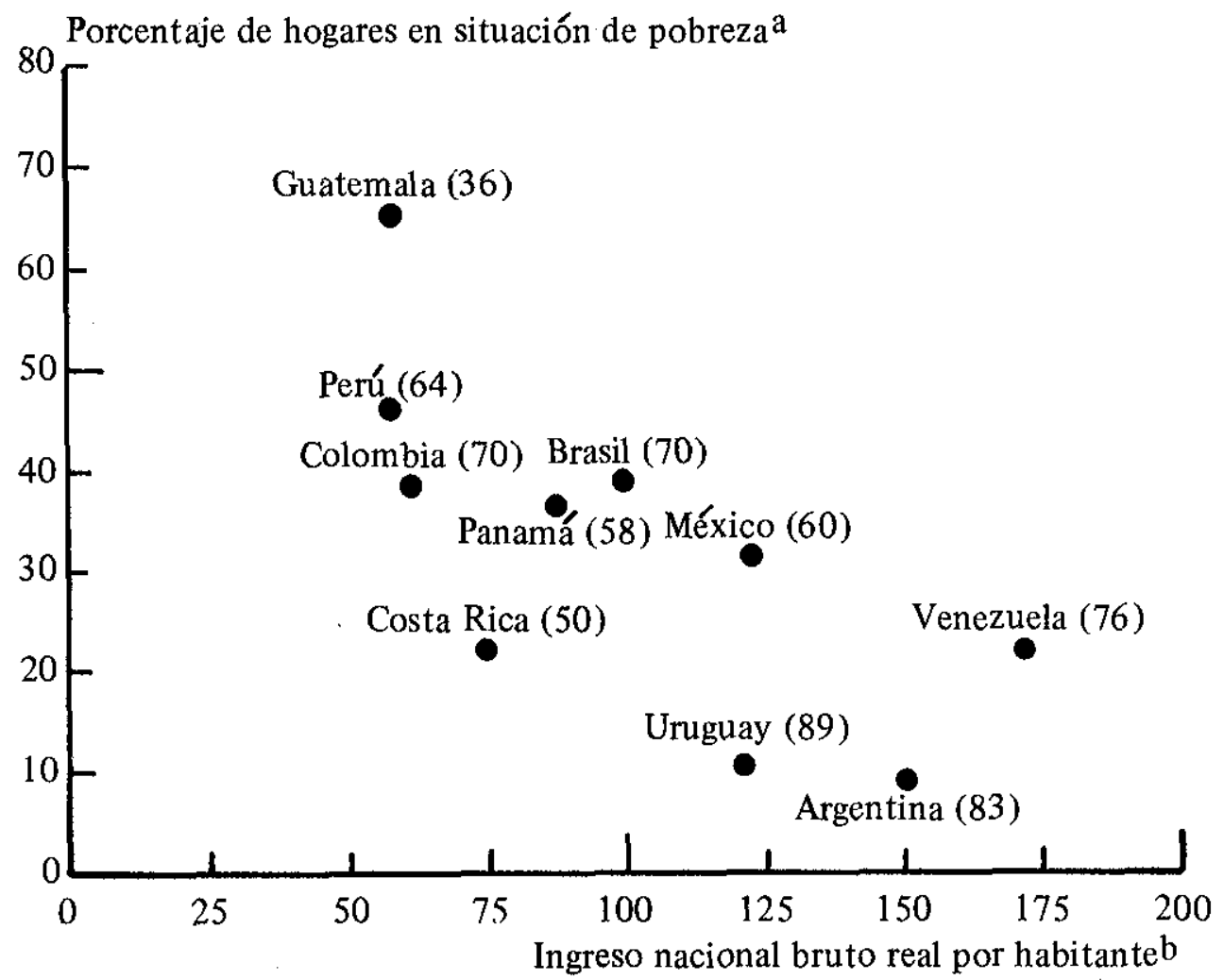

Fuente: cr.Pal, División de Estadística y Proyecciones.

a Entre paréntesis se indica el porcentaje de hogares urbanos.

b Promedio de 19 países de América Latina $=100$.

pleo urbano siguió siendo relativamente alto en ambos países, con tasas que oscilaban en promedio, entre 10 y $13 \%$. Por último, en México, donde se contó con antecedentes relativos sólo al conjunto del país, la pobreza se redujo entre 1977 y 1984 en dos puntos porcentuales.

Una apreciación global de estas estimaciones permite inferir que ellas captan adecuadamente la dimensión estructural del fenómeno de la pobreza. En tal sentido cabe destacar, por ejemplo, la estrecha relación que guardan los porcentajes de pobreza con sus determinantes más directos, esto es, el monto del ingreso por habitante, el nivel de concentración de su distribución y el grado de urbanización (Ahluwalia, 1976). El grá- fico 1 permite ilustrar algunas de estas relaciones. En él se muestra, en efecto, la alta correlación inversa existente entre el nivel del ingreso nacional bruto por habitante - expresado como índice respecto del promedio de América Latina-y la incidencia de la pobreza en cada uno de los países alrededor de 1980. En este gráfico se indican también los porcentajes de población urbana de cada país, que covarían directamente con el nivel del ingreso e inversamente con la pobreza.

Por otra parte, las cifras revelan que la población pobre del conjunto de los 10 países considerados, que era de 109 millones en los años cercanos a 1980, pasó a ser de 137 millones en los años 
en torno a 1986 , lo que significa un incremento de cerca de 28 millones de personas. ${ }^{15}$ A su vez, el carácter más bien urbano de la crisis a que hemos hecho mención modificó en forma importante la distribución de la población en condiciones de pobreza dentro de cada país. Mientras en 1980 el $48 \%$ de los pobres residía en zonas urbanas (53 millones de personas), en 1986 lo hacía el $58 \%$ (80 millones). Asimismo, como era de prever, casi la mitad de los pobres correspondía en uno y otro año a Brasil, y entre 85 y $90 \%$ de los mismos a cuatro de los 10 países considerados (Brasil, Colombia, México y Perú) (cuadro 5). La población indigente, por su lado, aumentó de 47 millones de personas en 1980 a 63 millones en 1986, lo que representa más de la mitad del incremento del conjunto de la población pobre. Al mismo tiempo, la pobreza, pese a crecer más en las zonas urbanas, siguió siendo más aguda en las zonas rurales: en éstas, en efecto, cerca de $55 \%$ del total de los pobres eran indigentes, mientras que en las zonas urbanas esa proporción alcanzaba a alrededor de $35 \%$.

Ahora bien, dado el indudable interés que despierta la posibilidad de disponer de una estimación agregada de la pobreza para el conjunto de la región, y teniendo en cuenta además que los 10 países ya mencionados representan un alto porcentaje de la población y del producto regionales $(85$ y $91 \%$, respectivamente), se procedió a extender, mediante una extrapolación, las cifras de pobreza de los primeros 10 países a un conjunto formado por 19 países de la región. Aparte de los 10 ya conocidos, los países que se incorporaron en esta estimación fueron Bolivia, Chile, Ecuador, El Salvador, Haití, Honduras, Nicaragua, Paraguay y República Dominicana. En esta extrapolación se emplearon como referencia ecuaciones de regresión que relacionan el producto interno bruto por habitante en $1980 \mathrm{y}$ 1986 con los porcentajes de hogares pobres e indigentes en los ámbitos nacional y urbano de los mismos años. ${ }^{16}$ Las estimaciones de pobreza

\footnotetext{
${ }^{15}$ Con el objeto de realizar las comparaciones pertinentes. estos cálculos se basaron en las cifras de población de los años 1980 y 1986 .

${ }^{16}$ Las ecuaciones fueron del tipo: $\mathrm{H}=\mathrm{a}+\mathrm{b}\left(\ln P I B_{\mathrm{pc}}\right)$ clonde: $\mathrm{H}=$ porcentaje de pobreza (o indigencia) y $\ln \mathrm{PIB}_{1 x}$ = logaritmo natural del producto interno bruto por habitante. Los valores de $r^{2}$ variaron entre 0.6 y 0.7 . La población
}

rural se obtuvieron residualmente, a partir de la distribución de la población por áreas geográficas. Los resultados se resumen también en el cuadro 5 .

Si se comparan las incidencias de pobreza obtenidas para los 19 países (que están muy cerca de representar el conjunto de la región) con las correspondientes al grupo de los 10 primeros, puede constatarse que hubo aumentos del orden de dos puntos porcentuales en ambos años. Este incremento se produjo porque, a pesar de la poca gravitación que tiene la población de los nueve países recién introducidos en la población regional, sus índices de pobreza fueron, por el contrario, superiores en promedio a los de los primeros 10 países. De acuerdo con estas extrapolaciones, en 1980 había en América Latina 135.9 millones de personas en la pobreza, esto es, $41 \%$ de la población total, cifra que se elevó a 170.2 millones de personas en 1986, pasando a representar asi $43 \%$ del total. Cabe destacar que el incremento de 34.3 millones de pobres se concentró casi en su totalidad en las zonas urbanas, donde la incidencia de la pobreza subió de 30 a $36 \%$. Ahora bien, los cambios relativos a la población en condiciones de indigencia revelan indirectamente, por su lado, la profundidad de la crisis durante el primer quinquenio de los años ochenta. En efecto, de ese incremento de 34.3 millones, 19 millones, esto es, $55 \%$, corresponden al aumento de la población indigente tanto urbana como rural.

\section{La evolución de la pobreza} en América Latina entre 1970 y 1986.

Su proyección hacia fines de los años ochenta

Los resultados de este análisis respecto de la magnitud de la pobreza en 1980 y 1986 pueden compararse, no obstante algunas diferencias metodológicas entre una y otra investigación, con los del estudio CEPAL-70. ${ }^{17}$

pobre e indigente de los nueve países no incluidos en el presente estudio se obtuvo aplicando a la población de cada país las incidencias de pobreza e indigencia estimadas mediante estas ecuaciones. En el caso de los hogares, los cálculos se basaron en datos provenientes de los últimos censos de población y, asimismo, en las relaciones de tamaños medios de las familias según los estratos de pobreza observados en países similares.

${ }^{17}$ Estas dicen relación principalmente con el procedimiento que se utilizó para elaborar las canastas básicas de 
Cuadro 5

AMERICA LATINA Y EL CARIBE: ESTIMACIONES DE POBREZA E INDIGENCIA, 1980 y 1986

\begin{tabular}{|c|c|c|c|c|c|c|c|c|}
\hline & \multicolumn{4}{|c|}{ Pobreza } & \multicolumn{4}{|c|}{ Indigencia } \\
\hline & \multicolumn{2}{|c|}{1980} & \multicolumn{2}{|c|}{1986} & \multicolumn{2}{|c|}{1980} & \multicolumn{2}{|l|}{1986} \\
\hline & Miles & $\%$ & Miles & $\%$ & Miles & $\%$ & Miles & $\%$ \\
\hline \multicolumn{9}{|c|}{ (Hogares) } \\
\hline \multicolumn{9}{|l|}{ Diez países" } \\
\hline Nacional & 19700 & 33 & 26500 & 35 & 8000 & 13 & 11700 & 15 \\
\hline Urbano & 10000 & 24 & 16200 & 29 & 3200 & 8 & 6000 & 11 \\
\hline Rural & 9700 & 52 & 10300 & 51 & 4800 & 26 & 5700 & 28 \\
\hline \multicolumn{9}{|c|}{ América Latina' } \\
\hline Nacional & 24200 & 35 & 32100 & 37 & 10400 & 15 & 14600 & 17 \\
\hline Urbano & 11800 & 25 & 18700 & 30 & 4100 & 9 & 7000 & 11 \\
\hline Rural & 12400 & 54 & 13400 & 53 & 6300 & 28 & 7600 & 30 \\
\hline \multicolumn{9}{|c|}{ (Población) } \\
\hline \multicolumn{9}{|l|}{ Diez. Países" } \\
\hline Nacional & 109200 & 38 & 137500 & 41 & 47400 & 17 & 62700 & 19 \\
\hline Urbano & 52800 & 28 & 80300 & 34 & 17300 & 9 & 29700 & 13 \\
\hline Rural & 56400 & 58 & 57200 & 57 & 30100 & 31 & 33000 & 33 \\
\hline \multicolumn{9}{|c|}{ América Latinab } \\
\hline Nacional & 135900 & 41 & 170200 & 43 & 62400 & 19 & 81400 & 21 \\
\hline Urbano & 62900 & 30 & 94400 & 36 & 22500 & 11 & 35800 & 14 \\
\hline Rural & 73000 & 60 & 75800 & 60 & 39900 & 33 & 45600 & 36 \\
\hline
\end{tabular}

Fuente: Estimaciones de la cepal.

it Argentina, Brasil, Colombia, Costa Rica, Guatemala, México, Panamá, Perú, Uruguay y Venezuela.

b Incluye, además de los diez primeros países, a Bolivia, Chile, Ecuador, El Salvador, Haití, Honduras, Nicaragua, Paraguay y República Dominicana.

Las cifras relativas a los países y áreas geográficas en que es posible llevar a cabo esa comparación revelan que, entre 1970 y 1980 , la pobreza urbana disminuyó en Brasil, Colombia, Uruguay y Venezuela, en magnitudes que fluctúan entre uno y cinco puntos porcentuales, en tanto que en Argentina, Costa Rica y Perú aumentó entre uno y siete puntos (cuadro 6). En las áreas rurales, por su lado, la pobreza descendió en todos los países, en un rango que va de 1 a 11 puntos porcentuales. Estas cifras se refieren lógicamente a un promedio nacional, donde inciden también las variaciones en la distribución de la población entre ambas áreas, dado que en esa década continuó -con diverso ritmo en cada país- el proceso de urbanización.

alimentos. Para una reseña de tales diferencias, véase cripa. 1990 (Apéndice).
Lo ocurrido entre 1970 y 1986 sigue, a su vez, la evolución del ingreso de los distintos países en los dos subperíodos antes mencionados, 1970-1980 y 1980-1986. Así, aquellos países que tuvieron en esos años los índices más elevados de crecimiento sostenido (Brasil y Colombia), fueron precisamente los que exhibieron mayores reducciones en la magnitud de la pobreza. Los antecedentes relativos a la distribución del ingreso indican que estos dos países siguieron figurando entre aquéllos con mayor grado de concentración distributiva de la región, lo que admite conjeturar que la mejoría en sus índices de pobreza descansó mucho más en el incremento de los niveles de ingreso que en avances significativos en el sentido de una mayor equidad. ${ }^{18}$ Cabe recordar, además, que Brasil y Colombia no atra-

\footnotetext{
${ }^{18}$ Véase, por ejemplo, CEPAL, 1986 a y CEPAL, 1986 b.
} 
Cuadro 6

AMERICA LATINA (DIEZ PAISES): MAGNITLD DE LA POBREZA E INDIGENCIA ALREDEDOR DE 1970, DE 1980 Y DE 1986

\begin{tabular}{|c|c|c|c|c|c|c|c|c|c|c|c|c|c|c|c|c|c|c|}
\hline \multirow{3}{*}{ País } & \multicolumn{9}{|c|}{ Porcentaje de hogares bajo la línea de pobreza } & \multicolumn{9}{|c|}{ Porcentaje de hogares bajo la línea de indigencia } \\
\hline & \multicolumn{3}{|c|}{$\begin{array}{c}\text { Area } \\
\text { urbana }\end{array}$} & \multicolumn{3}{|c|}{$\begin{array}{l}\text { Area } \\
\text { rural }\end{array}$} & \multicolumn{3}{|c|}{$\begin{array}{l}\text { Total } \\
\text { pais }\end{array}$} & \multicolumn{3}{|c|}{$\begin{array}{c}\text { Area } \\
\text { urbana }\end{array}$} & \multicolumn{3}{|c|}{$\begin{array}{l}\text { Area } \\
\text { rural }\end{array}$} & \multicolumn{3}{|c|}{$\begin{array}{l}\text { Total } \\
\text { país }\end{array}$} \\
\hline & 1970 & 1980 & 1986 & 1970 & 1980 & 1986 & 1970 & 1980 & 1986 & 1970 & 1980 & 1986 & 1970 & 1980 & 1986 & 1970 & 1980 & 1986 \\
\hline Argentina & 5 & 7 & 12 & 19 & 16 & 17 & 8 & 9 & 13 & 1 & 2 & 3 & 1 & 4 & 6 & $\mathbf{l}$ & 2 & 4 \\
\hline Brasil & 35 & 30 & 34 & 73 & 62 & 60 & 49 & 39 & 40 & 15 & 10 & 13 & 42 & 35 & 34 & 25 & 17 & 18 \\
\hline Colombia & 38 & 36 & 36 & 54 & 45 & 42 & 45 & 39 & 38 & 14 & 13 & 15 & 23 & 22 & 22 & 18 & 16 & 17 \\
\hline Costa Rica & 15 & 16 & 21 & 30 & 28 & 28 & 24 & 22 & 25 & 5 & 5 & 6 & 7 & 8 & 10 & 6 & 6 & 8 \\
\hline Perú & 28 & 35 & 45 & 68 & 65 & 64 & 50 & 46 & 52 & 8 & 12 & 16 & 39 & 37 & 39 & 25 & 21 & 25 \\
\hline Uruguay & 10 & 9 & 14 & - & 21 & 24 & - & 11 & 15 & 4 & 2 & 3 & - & 7 & 8 & - & 3 & 3 \\
\hline Venezuela & 20 & 18 & 25 & 36 & 35 & 34 & 25 & 22 & 27 & 6 & 5 & 8 & 19 & 15 & 14 & 10 & 7 & 9 \\
\hline América Latina & 26 & 25 & 30 & 62 & 54 & 53 & 40 & 35 & 37 & 10 & 9 & 11 & 34 & 28 & 30 & 19 & 15 & 17 \\
\hline
\end{tabular}

Fuente: Estimaciones de la CEPAL. Las cifras para 1970 corresponden a las estimaciones publicadas en La dimensión de la pobreza en América Latina, serie Cuadernos de la CEPAL, $\mathrm{N}^{\circ} 27$, Santiago de Chile, 1979.

a Sólo se dispuso de antecedentes a nivel nacional. 
vesaron durante los años ochenta por un período recesivo de la profundidad del que conoció la mayoría de los restantes países. Asimismo, la reducción algo menor de la pobreza en México - con un grado de concentración intermedio en la región- podría explicarse no sólo por el fuerte incremento del ingreso durante el período, sino también por aumentos de la participación de los hogares pertenecientes a los tramos más bajos de la distribución. De hecho, hay antecedentes que indican, por un lado, que efectivamente hubo en México una disminución entre fines de los años sesenta y fines de los setenta, del grado de concentración de la distribución del ingreso, y, por otro, que esta distribución se mantuvo relativamente inalterada desde esa fecha hasta 1984 (Altimir, 1982).

Lin el cuadro 6 puede constatarse, asimismo, que la pobrèa aumentó en el período 1970-1986 en los otros cinco países, incremento que guarda relación con el hecho de que el ingreso haya sufrido ell éstos caídas más fuertes durante los años de crisis. Argentina constituye indudablemente el caso extremo en tal sentido: la pobre za a nivel nacional se elevó aquí, en efecto, en cinco puntos porcentuales, a causa de la marcada reducción del ingreso per cápita ( $15 \%$ respecto de $1970) \mathrm{v}$ (lel deterioro en su distribución. ${ }^{1 ! 9} \mathrm{kn}$ Costa Kica. Perú y Venezuela el aumento de la pobreza fluctuó entre uno y dos puntos, al tiempo que los niveles de ingreso nacional per cápita alcanzados el ano final de estimación prácticamente no difirieron de los de 1970. Estos países presentaron aumentos importantes del ingreso en los años setenta - con excepción de Perú-, pero experimentaron fuertes reducciones del mismo en el curso de los años ochenta, presumiblemente acompañadas de un aumento en la concentración distributiva. Algo similar ocurrió en el caso de Uruguay en relación con la pobreza urbana.

Ahora bien, las cifras relativas a los 19 países de la región muestran claramente la distinta evo-

\footnotetext{
${ }^{19}$ Estimaciones de la distribución del ingreso total de los hogares del Gran Buenos Aires indican que el coeficiente de concentración de Gini subió de 0.41 en 1970 a 0.44 en 1975 y 0.47 en 1980 (Altimir, 1986). En el presente estudio, en tanto, se estimó que el mismo coeficiente, referido esta vez a la distribución del ingreso per cápita de los hogares, aumentó de 0.38 en 1980 a 0.41 en 1986 .
}

lución seguida por la pobreza en las dos décadas comparadas. En efecto, durante los años setenta el porcentaje de los hogares pobres se redujo de 40 a $35 \%$, y de 19 a $15 \%$ el de los hogares indigentes. La tendencia se revirtió, en cambio, durante los años ochenta, puesto que tanto la pobreza como la indigencia se incrementaron en dos puntos porcentuales. Dichas magnitudes son, a su vez, el resultado de evoluciones muy distintas según se trate de zonas urbanas o rurales. Así, el que la crisis haya afectado relativamente más a los hogares de las zonas urbanas, unido al aumento en prácticamente todos los países de la proporción representada por la población urbana dentro de la población total, contribuye a explicar el hecho de que la pobreza se haya incrementado, entre 1970 y mediados del decenio de 1980 , en cuatro puntos porcentuales (de 26 a $30 \%$ ) en esas áreas, a pesar incluso de la reducción de un punto porcentual que había experimentado durante la década de 1970. En las zonas rurales, en cambio, sin olvidar ciertamente el carácter más conjetural de estas estimaciones, se produjo una considerable reducción de la pobreza durante los años setenta (de 62 a $54 \%$ ), y una relativa estabilidad durante los ochenta (cuadro $6)$.

Por otra parte, con el objeto de contar con una estimación que permitiera apreciar lo ocurrido con la pobreza en los 19 países de la región durante las décadas de 1970 y 1980 , se realizó una provección al año 1989 de la incidencia de pobreza en cada país. Esta se basó tanto en la evolución del producto por habitante como en la de otros indicadores generales (desempleo abier(1), remuneraciones medias, salarios mínimos, porcentaje de población rural y producto por sector de actividad económica) a lo largo del trienio 1986-1989.

De acuerdo con esta proyección, al término de los años ochenta 37\% de los hogares de América Latina y el Caribe se encontraría en condiciones de pobreza y $17 \%$ en condiciones de indigencia (cuadro 7). En las zonas urbanas estos porcentajes llegan a $31 \%$ para la pobreza y a $12 \%$ para la indigencia, y a 54 y $31 \%$, respectivamente, en las áreas rurales. Comparadas con las de 1970, estas cifras indican un fuerte aumento de la pobreza urbana (de 26 a $31 \%$ ), y una baja, también significativa, de la pobreza rural (de 62 a $54 \%$ ). Cambios en el mismo sentido, pero de menor magni- 
Cuadro 7

AMERICA LATINA Y EL CARIBE: MAGNITUD DE LA POBREZA EN 1989

(Proyecciones a partir de cifras de 1986)

\begin{tabular}{|c|c|c|c|c|c|c|c|c|}
\hline & \multicolumn{4}{|c|}{ Hogares } & \multicolumn{4}{|c|}{ Población } \\
\hline & \multicolumn{2}{|c|}{ Pobreza } & \multicolumn{2}{|c|}{ Indigencia } & \multicolumn{2}{|c|}{ Pobreza } & \multicolumn{2}{|c|}{ Indigencia } \\
\hline & Miles & $\%$ & Miles & $\%$ & Miles & $\%$ & Miles & $\%$ \\
\hline Total & 34600 & 37 & 15800 & 17 & 183200 & 44 & 87700 & 21 \\
\hline Urbano & 20300 & 31 & 7600 & 12 & 103700 & 36 & 39400 & 14 \\
\hline Rural & 14300 & 54 & 8200 & 31 & 79500 & 61 & 48300 & 37 \\
\hline
\end{tabular}

Fuente: Estimaciones de la cEPAL.

tud, se habrían producido en cuanto a la indigencia. Como consecuencia del aumento de la población y de los índices de pobreza, hacia fines de los años ochenta habría habido cerca de 183 millones de personas pobres en la región, esto es, 71 millones más que en 1970. De éstas, alrededor de 88 millones serían indigentes, cifra que indica un aumento cercano a 28 millones respecto del volumen estimado por la cresar. para ese año.

Una de las constataciones más que surgen de esta comparación es que, a diferencia de lo que ocurría en 1970, la pobreza en la región es hoy un fenómeno mayoritariamente urbano, a causa de la fuerte expansión de sus principales ciudades -en los últimos 20 años la población urbana en la región pasó de 58 a $69 \%$ de la población total$y$ del hecho de que el incremento de los índices de pobreza se haya concentrado fundamentalmente en esas zonas, en especial durante el período de crisis. Así, mientras en 1970 sólo $37 \%$ de los pobres residía en las zonas urbanas, más de la mitad $(57 \%)$ lo hace actualmente. Si se centra la atención en los extremadamente pobres o indigentes puede afirmarse, al contrario, que hoy, tal como en 1970, la mayoría de éstos sigue residiendo en las áreas rurales, a pesar del aumento (de 31 a $45 \%$ ) que ha experimentado la proporción de indigentes urbanos dentro de la masa total de indigentes.

Estas cifras globales están, sin cluda, asociadas con el virtual estancamiento que ha experimentado el producto por habitante en América Latina durante el período 1970-1989. En efecto, excluyendo a Brasil, el producto creció en ese lapso sólo $3.2 \%$ en términos reales, al tiempo que el nivel alcanzado en 1989 era más de $12 \%$ inferior al que se había logrado en 1980. La mayor parte de esta baja se produjo, en casi todos los países, en un lapso relativamente breve, dos a tres años, y estuvo acompañada por reducciones más que proporcionales del ingreso de los sectores más pobres. Esta circunstancia, unida al carácter de la crisis, explica el crecimiento de los indices de pobreza en el plano nacional y particularmente en el urbano. Por otro lado, el aumento experimentado en las últimas dos décadas por el ingreso per cápita en las zonas rurales contribuye, sin duda, a explicar el descenso de la pobreza en esas zonas. En la década de los ochenta, el valor agregado generado en la agricultura -por habitante rural- creció en cerca de $14 \%$, mientras se reducía en un porcentaje similar el generado fuera de ella (вıD, 1989). Con todo, entre 1970 y 1989 el número de pobres rurales aumentó en América Latina en alrededor de 9 millones de personas.

Por último, cabe llamar la atención también solore la notable asimetría que hay entre la evolución de la pobreza urbana de América Latina y los cambios acontecidos en el ingreso durante los dos subperiodos que consideramos. ${ }^{20}$ En los años setenta, aunque el ingreso per cápita de la región

\footnotetext{
${ }^{20}$ Las tendencias observadas en los ocho países confirman esa aseveración. Len el caso de Brasil, el país de mayon gravilación en la cifra agregada a nivel regional, los cinco puntos de disminución de la pobreza urbana entre 1970 y 1979, atribuibles principatmente al fuerte crecimiento del ingreso por habitante en ese períoclo (de 1100 a 1850 dóla res a precios de l980), prácticamente desaparecieron en los ocho anos siguientes. Aunque en 1987, tras la fiterte caida experimentada ente 1980 y 1983 , el ingreso habia recuperado el nivel de 1979. las remuneraciones medias y el salario mínimo urbano se situaron ese año cn los niveles más bajos alcamzados en la década de 1980.
} 
se expandió a un ritmo relativamente elevado (a un promedio de $3.6 \%$ anual), la pobreza se redujo sólo en un punto porcentual. En la primera mitad de los años ochenta, en cambio, la disminución del ingreso por habitante (a un promedio de $2.3 \%$ anual) estuvo acompañada de un incremento de cinco puntos porcentuales en la pobreza urbana. Estas mejoras y retrocesos están ciertamente asociados también con las tendencias exhibidas por là distribución del ingreso. A modo de hipótesis, toda vez que no se disponen de antecedentes sobre los patrones distributivos imperantes en los años cercanos a 1970 que sean comparables con las estimaciones efectuadas para mediados de los años ochenta, podría afirmarse que la reducción de la pobreza que conocieron algunos países durante la década de 1970 ocurrió sin que se modificaran mayormente los patrones distributivos, esto es, permaneciendo inalterados los altos niveles de concentración característicos de la región. Brasil y Colombia parecen constituir los casos más notables en tal sentido, puesto que los efectos del llamado derrame operaron básicamente en función del ritmo de crecimiento de esas economías. Los conocidos y abundantemente analizados efectos de la crisis, especialmente en los estratos bajos de la población urbana, pueden explicar el hecho de que durante los años ochenta la caída del ingreso y del consumo haya sido aún más acentuada en los deciles inferiores de la distribución, incrementando así la pobreza y los ya elevados niveles de desigualdad. Argentina y Uruguay, que presentaban los patrones de ingreso comparativamente más equitativos de América Latina, sufrieron retrocesos importantes en esta materia, adquiriendo un perfil más cercano al de los países con grados de concentración intermedia. En consecuencia, es muy probable que a comienzos de la presente década varios paises de la región, particularmente aquellos en los que los ajustes de sus economías han significado caídas más pronunciadas del ingreso, presenten un grado de inequidad distributiva mayor que el existente alrededor de 1980, e índices de pobreza, en especial urbana, igualmente más elevados.

\section{Bibliografía}

Ahluwalia, Montek (1976): ' Inequality, poverty and development, foumal of Development Econsmics, vol. 3, $\mathrm{N}^{\circ} 4$, Amsterdam, North-Holland Publishing Company, diciembre.

Altimir, Oscar (1987), Income distribution statistics in Latin America and their reliability, The Review of Income and Wealth, Serie $33, \mathrm{~N}^{\circ} 2$, junio.

(1986): Estimaciones de la distribución del ingreso en la Argentina, 1953-1980, Desarrollo económico, Instituto de Desarrollo Económico y Social (IDFS), vol. 25, $\mathrm{N}^{\circ} \mathrm{l00}$, Buenos Aires, enero-marzo.

(1982); La distribución del ingreso en México, 1950-1977, Distribución del ingreso en México. Ensayos. Banco de México, cuaderno 2, tomo 1, México, D.F.

(1979): La dimensión de la pobreza en América Latina, serie Cuadernos de la (:FAl., N" 27, Santiago de Chile, Comisión Económica para América Latina y el Caribe (CFPNL).

BI1) (Banco Interamericano de Desarrollo) (1989): El $\mathrm{km}$. Auge agrícola en América Latina, Washington, D.C.., marzo.

(E) Al (Comisión Econónica para América Latina y el Caribe) (1990): Magnitud de la pobreza en América Latina en los años ochenta (t.../... 533), Santiago de Chile, junio.

(1989 a). Cuentas de ingresos y gastos de los hogares de nueve paises latinoamericanos (1.c/L.. 530), Santiago de Chile, diciembre.

(1989 b): Balance preliminar de la economía de América Latina y el Caribe 1989 (t.c/(. 1586), Santiago de Chile, diciembre.

(1988): Determinación de las necesidades de energía y proteinas para la población de nueve países latinoamericanos (1.c/1.. 471), Santiago de Chile, julio.

( 1986 a): Antecedentes estadísticos de la distribución del ingreso. Colombia 1951-1982 (tc/s. 1385), Santiago de Chile, enero.

(1986 b): Antecedentes estadísticos de la distribución del ingreso. Brasil 1960-1983 (Lc/(r. 1387), Santiago de Chile, septiembre.

Holoms (Organización de las Naciones Unidas para la Agricultura y la Alimentación/Organización Mundial de la Salud) (1973): Necesidades de energía y de protemas, Informe de un Comité Especial Mixto faoloms de Expertos, Serie de informes técnicos, $N^{\text {" } 522, ~ R o m a . ~}$

$\mathrm{Mo} / \mathrm{OMS} / \mathrm{t}$ Ne (Organización de las Naciones Unidas para la Agricultura y la Alimentación/Organización Mundial de la Salud/Universidad de las Naciones Unidas) (1985): Necesidades de energía y de proteinas, Informe de una Reunión Consultiva Conjunta raolomsionu de Expertos, Serie de informes técnicos, $\mathrm{N}^{\circ} 724$, Ginebra. 